\title{
A ESTRANHEZA DO MÉDICO FRENTE À MORTE: LIDANDO COM A ANGÚSTIA DA CONDIÇÃO HUMANA ${ }^{1}$
}

\author{
The Doctor Facing Death: Dealing with Angst of the Human Condition
}

La Extrañeza de los Médicos Frente a Muerte: Enfrentando la Angustia de la Condición Humana

Aline Andressa Martinez Mello

LuCia Cecilia da Silva

\begin{abstract}
Resumo: Este relato se refere a uma pesquisa que realizamos com o objetivo de compreender a vivência do médico diante da morte. Adotou-se uma metodologia qualitativa na qual o referencial de análise escolhido foi a fenomenologia ontológica de Heidegger. A coleta de dados se deu por meio de entrevistas e os sujeitos foram dez médicos do Hospital Universitário Regional de Maringá (PR). Os resultados foram expressos em unidades de significado que sintetizaram as experiências de angústia e de estranheza frente a morte, bem como os sentimentos despertados ao lidar com a morte na prática médica, a preocupação com os procedimentos, a dificuldade em lidar com a morte de crianças e a falta de preparo na formação. $\mathrm{O}$ estudo aponta para a necessidade de criação de espaços para compartilhamento de experiências desde a graduação, contribuindo para uma atenção mais cuidadosa aos pacientes, e principalmente com a saúde mental do profissional.
\end{abstract}

Palavras-chave: Fenomenologia; Morte; Medicina; Angústia.

Abstract: This report refers to a survey we conducted in order to understand the experience of the physician facing death. We adopted a qualitative methodology in which the analytical framework chosen was Heidegger's ontological phenomenology. Data collection was through interviews and the subjects were ten physicians from University Hospital of Maringá (PR). The results were expressed as units of meaning that summarized the experiences of anxiety and awkwardness in the face of death and the feelings aroused when dealing with death in medical practice, the concern with the procedures, the difficulty in dealing with the death of children lack of preparation and training. The study points to the need to create spaces for sharing experiences since graduation, contributing to a more careful attention to patients, and especially with the professional's mental health.

Keywords: Phenomenology; Death; Medicine; Angst.

Resumen: Este informe se refiere a una encuesta que llevamos a cabo con el fin de comprender la experiencia de la muerte que el médico enfrenta. Hemos adoptado una metodología cualitativa en que el marco analítico elegido fue la fenomenología ontológica de Heidegger. La recolección de datos fue a través de entrevistas y los sujetos fueron diez médicos del Hospital Universitario de Maringá (PR). Los resultados se expresaron como unidades de sentido que resume las experiencias de ansiedad e incomodidad en el rostro de la muerte y los sentimientos para hacer frente a la muerte en la práctica médica, la preocupación acerca de los procedimientos, la dificultad de relacionarse con la muerte de los niños, falta de preparación y formación. El estudio apunta a la necesidad de crear espacios para compartir experiencias desde su graduación, lo que contribuye a una atención más cuidadosa a los pacientes, y especialmente con la salud mental de lo profesional.

Palabras-clave: Fenomenología; Muerte; Medicina; Angustia.

\section{Introdução}

A morte é um assunto ainda difícil de ser tratado, mesmo pelos os médicos que a tem como elemento não só da vida, mas também do ofício. A relação entre morte e atuação médica sofreu diversas modificações no decorrer de nossa história. Zaidhaft (1990) cita que até o século XIX, a única função do médico em relação à morte era a de espectador, e que isso só foi se modificando a partir do século XVIII, com o desenvolvimento científico e tecnológico e a institucionalização do doente no hospital.

1 Artigo elaborado a partir do relatório de um projeto de pesquisa (PIBIC), financiado pela Fundação Araucária e desenvolvido na Universidade Estadual de Maringá.
Podemos dizer que a concepção que temos da morte é histórica, pois também é determinada pelo momento em que vivemos, pelos conhecimentos, crenças e valores de uma época. Assim, o avanço da medicina a partir dos estudos da Anatomia, após o movimento Renascentista, instaurou uma nova maneira de conceber o homem e a relação com suas doenças por meio de uma racionalidade médica pautada basicamente no mecanismo fisiologista. Isso fez com que o indivíduo passasse a ser considerado um "receptáculo" de doenças, sendo que tais doenças ao serem estudadas a partir do corpo do morto, possibilitaram o pensamento de que a doença leva à morte e a vida seria a consequência da eliminação de todos os sintomas dessa enfermidade, o que caracteriza, nesta abordagem, a cura. 
O médico foi estimulado a focar sua atenção nas doenças, dando menos importância ao aspecto humano que há nelas, fazendo com que o paciente fosse visto "apenas como o portador de uma doença" (Koifman, 2001). Dessa maneira, segundo a autora, instaurou-se na medicina moderna o modelo biomédico que pressupõe que o corpo humano precisa constantemente de inspeção por parte dos especialistas médicos, inferindo que alguma coisa não estará em seu funcionamento perfeito. Nesse sentido, o trabalho do médico consiste em esforços cada vez maiores para interromper os processos degenerativos e destruir os invasores, impedindo que a morte aconteça.

Não podemos deixar de perceber que isso ainda é reforçado no ensino médico. A grade curricular e os fatores envolvidos na aprendizagem e formação do médico são bastante responsáveis por essa maneira de empregar o esforço laboral em busca da cura como se fosse a única alternativa possível. A respeito disso, Koifman (2001) discorre que as disciplinas calcadas na visão biologicista, a ênfase às especialidades e o ensino teórico contribuem para que a instrução dada ao acadêmico de medicina seja feita concebendo a fragmentação da relação saúde-doença. Trabalham assim, de maneira prática e técnica, com predominância de fundamentos organicistas, e porque não dizer, reducionistas, pois concebem o indivíduo apenas sob o ângulo de sua enfermidade e reduzem os cuidados à busca da cura desconsiderando que a morte é um processo da própria vida. Assim,

(...) tudo se passa como se o médico aprendesse a discorrer sobre as doenças para esquecer o fato definitivo da morte. Esse esquecimento, porém, afasta a medicina de um aspecto essencial da natureza humana: a consciência da fragilidade, a certeza da morte (Koifman, 2001, p. 8).

Dessa maneira os médicos, em sua formação, não são preparados para lidar com a morte como sendo um fator inerente à condição humana, e na busca de vencê-la muitas vezes esquecem que estão lutando contra o invencível. Deste modo,

(...) com a deficiência desta formação acadêmica, que não prepara os futuros médicos e profissionais da saúde para compreender melhor o processo de Morte e Morrer, o que vemos é um "olhar defeituoso" ante a morte de um paciente. Cada vez que o médico consegue a cura de seu enfermo, é uma vitória pessoal contra sua própria morte. Quando a morte ganha a batalha, leva o doente e o médico (Bifulco, 2006, p. 166).

Ainda sobre a formação acadêmica e constituição do sujeito enquanto médico, Zaidhaft (1990), afirma que o estudante de Medicina tem seu primeiro conta- to com um cadáver ao ingressar na Faculdade, e nesse encontro com o cadáver, inicia-se nos alunos o processo de desenvolvimento de mecanismos de defesa indispensáveis para a futura profissão. Cabe salientar que o acadêmico se faz médico nas relações identificatórias com professores e com outros alunos assumindo sua "identidade médica" também a partir das atitudes dos que lhe servem de espelho incorporando assim, a ideologia médica.

Esta ideologia, transmitida cotidiana e quase automaticamente, é expressa em máximas como "não se envolva com o paciente", "há que se ter sangue frio", "para aprender é assim mesmo", "se você ficar sofrendo a cada morte de paciente, você não agüenta e larga a Medicina" (Zaidhaft, 1990, p. 19).

Assim, o futuro médico é, desde o princípio, treinado para lidar com a morte de maneira prática, sendo acometido diariamente por estimulações que o incitam a esconder ou a aprender a não expressar seus sentimentos em relação à morte de um paciente. Segundo Silva (2006, p. 176), a morte com a qual os estudantes de medicina aprendem a lidar, é uma morte morta, sem alma, e quando se encontram de fato com a morte, com corpo e alma "os conflitos e paradoxos entre as concepções desejadas para esse enfrentamento e os pressupostos assimilados ganham expressão nas interações intersubjetivas concretamente vividas". Mascia et al. (2009) afirmam que "o profissional que não está devidamente preparado para lidar com essas situações poderá experimentar uma gama de sentimentos reativos" (p. 45) e que tais sentimentos podem se manifestar como perda do senso de missão, cinismo, desesperança, frustração, bem como risco aumentado de burnout e depressão.

Mas, aprendendo ou não, considerando ou não o assunto, o médico tem de lidar com a morte em seu ofício. $\mathrm{O}$ que acontece e como ele se sente quando se defronta com ela no seu cotidiano, quando a morte está ao alcance de seus olhos? Essa foi a questão que nos propomos a compreender neste estudo.

Certamente inúmeros sentimentos constituem a experiência do médico nesse lidar (ou não lidar) com a morte. Feijoo (1998), utilizando-se do referencial fenomenológico deixado por Heidegger, afirma que o homem é um ser disposto no mundo e que nessa abertura para o mundo, os sentimentos tornam-se a condição fundamental do existir. O medo, a angústia, o êxtase, a dor e muitos outros sentimentos constituem a existência humana.

Vivenciar os sentimentos relacionados à morte nos parece especialmente difícil para aqueles que são ensinados e treinados a se afastarem dela. Mas, como diz Zaidhaft (1990, p. 137), "por mais que o médico tente se 'dessubjetivar' a fim de se 'vacinar' contra a morte, isto não é psicologicamente viável". Sabendo disso e concordando com Klafke (1998), quando a autora afirma que todos se im- 
portam com os sentimentos do paciente e deixam de lado os sentimentos que o médico manifesta, esquecendo que esse também é um fator a ser considerado, nos motivamos a pesquisar a experiência do médico que, enquanto cuidador, está fadado a lidar diretamente com o sofrimento trazido pelas questões da morte e do morrer.

\section{Objetivos}

Segundo Heidegger, o saber-se mortal traz em si uma angústia existencial e para escapar dela o homem, muitas vezes, se refugia num cotidiano impessoal vivenciando as atividades de sua vida de modo deficiente. Pensando nisso, objetivamos compreender a vivência do médico, por meio de relatos de sua experiência profissional. A partir disso, objetivamos também, levantar aspectos relacionados à vivência profissional que dificultam ou facilitam o convívio com a morte no ofício, bem como aspectos na prática profissional que auxiliam o médico a lidar com a angústia de sua própria finitude.

\section{Metodologia}

Buscamos elaborar uma compreensão do fenômeno ser-médico-com-a-morte e para chegarmos a tal compreensão utilizamos a entrevista como meio de adentrar à vivência do profissional, acreditando que a palavra tem em si o poder de revelação dos sentidos mais próprios do sujeito, do ser-no-mundo. A entrevista foi realizada na modalidade aberta, com uma pergunta norteadora, a qual incitava os participantes a contarem sobre a sua experiência com a morte no cotidiano do trabalho.

Participaram da pesquisa dez médicos atuantes no Hospital Universitário Regional de Maringá (Paraná), todos do gênero masculino, pois nenhuma médica se dispôs a participar. O tempo de exercício da profissão variou de um período de três meses a 35 anos. Foram obedecidas as orientações constantes da Resolução 196/96 do Ministério da Saúde, respeitando os aspectos éticos com a Instituição que autorizou a pesquisa, e com os sujeitos que concordaram livremente em participar, assinando o Termo de Consentimento Livre e Esclarecido previamente aprovado pelo Comitê de Ética da Instituição de Ensino.

Os conteúdos das entrevistas foram transcritos de forma literal, respeitando o estilo próprio dos participantes, bem como momentos de silêncio e risos. Após leituras atentas das mesmas para que ficássemos impregnados dos conteúdos, analisamos os relatos procurando por divergências e convergências e elaboramos Unidades de Significado que possibilitaram o esclarecimento do fenômeno investigado. A seguir apresentamos e discutimos esses resultados.

\section{Resultados}

\subsection{A Angústia e a Estranheza do Médico frente à Morte}

Foi possível perceber que os médicos convivem com a morte com sentimentos de estranheza, e não com uma disposição de familiaridade como seria natural pensar, afinal, lidam com a possibilidade da morte mais frequentemente que os leigos, devido ao seu ofício. Diríamos que eles têm a possibilidade mais presente da morte pela própria natureza do seu trabalho cotidiano. Contudo, suas falas nos remetem ao entendimento de Heidegger (1927/2002) que, ao desvelar o ser-no-mundo que somos, desvela-se também a angústia como disposição fundamental desse ser-aí-no-mundo ante sua finitude. Essa presença no mundo que todos nós somos se angustia ao compreender-se mortal, tendente ao não-ser-mais-aí.

A angústia nos anuncia que o projeto existencial de cada presença no mundo é provisório e que cabe à presença, o cuidado, a responsabilidade pelo seu poder-ser. A angústia nos fala que na verdade, não somos agarrados a nada, nem ao mundo, já que a morte é certa. Para livrar-se da angústia a presença se refugia, distraidamente, na impessoalidade do cotidiano, "leva a vida", como diz Heidegger, fugindo do pensar sobre a possibilidade certa da morte para as atribulações da vida cotidiana. Nas entrevistas fica claro que sabendo-se ser-para-a-morte, o médico não se sente confortável ao tratar do assunto, esquivando-se dele de alguma maneira e salientando esse refúgio no cotidiano. Vejamos algumas manifestações dessa estranheza:

“...é uma coisa tão inesperada que... [silêncio]” (Cirurgião Geral, 35 anos de profissão).

"A morte é uma coisa que ninguém quer ver, nem ouvir, e muito menos sentir, não é mesmo?” (Oncologista, 20 anos de profissão).

"Não é nada agradável. A morte nunca é agradável (...), você tem que ser forte, mas você não tem preparação pra isso. Eu, por exemplo, eu detesto enterro, eu detesto essas coisas por que? Porque eu não sei nem o que falar, eu até falo pra minha esposa quando eu morrer, eu não quero enterro, quero ser cremado se pudesse, até dentro do hospital, e acabou, que eu não quero ninguém lá. A morte é uma coisa difícil!” (Pediatra, 20 anos de profissão).

"Ah, absolutamente nada... não sinto absolutamente nada. Porque, assim, se eu ficar me importando muito com essas coisas, vai atrapalhar demais meu trabalho e eu tenho muitos outros pra atender, muita coisa pra fazer. Se você ficar pensando demais nisso, atrapalha tudo, então eu não penso, deixo lá, não sinto nada" (Clínico Geral, 7 anos de profissão). 
"Eu... eu prezo muito pela vida deles, tento o máximo deixá-los vivos, mas eu procuro o mínimo possível me envolver com a morte deles, porque depois que eles morreram...ah...eu...ah...a gente... o envolvimento com a família e o excesso de afetividade com a família prejudica o trabalho que você tem com os pacientes" (Nefrologista e Clínico Geral, 20 anos de profissão).

Nas últimas falas é flagrante a experiência do médico, que ao pensar sobre a morte, transita do ser-si-próprio que a angústia possibilita - compreendendo-se que é ser-paraa-morte tal qual seu paciente -, para o impessoal, para o impróprio. Como continuar a trabalhar sentindo-se angustiado? Melhor não se deixar afetar e mergulhar "nas muitas coisas a fazer". Ao dizer:...ah...eu...ah...a gente... é a revelação da passagem do si-próprio, enquanto um "eu", uma "mindade", para o impessoal, o ninguém, o "a gente". Como afirma Silva (2009, p. 55-56) "o ser pre-sente no mundo, no geral, não tem a experiência de ser si mesmo. A experiência do si-mesmo é, na verdade, a experiência do a gente, do todos nós, do ninguém, enfim, o modo de ser impróprio, impessoal".

Diante da morte o médico se angustia. A angústia mostra ao próprio ser como ele está, ela "retira" o ser de sua impessoalidade. Na angústia a presença está estranha e não mais familiarizada, ou se sentindo em casa. A familiaridade cotidiana do impessoal é rompida quando a angústia dá à presença a possibilidade de voltar-se a si mesma. Ocorre um afastamento do mundo cotidiano e dos entes. A presença é si-própria e por se manifestar assim, também se sente estranha e ameaçada. A angústia clama por um questionamento acerca do próprio "mundo", da vida que se leva e da responsabilidade de cuidar dela. Heidegger (1927/2002) diz:

(...) na angústia o que se encontra à mão no mundo circundante, ou seja, o ente intramundano em geral, se perde. O "mundo" não é mais capaz de oferecer alguma coisa nem sequer a co-presença dos outros. A angústia retira, pois, da pre-sença a possibilidade de, na de-cadência, compreender a si mesma a partir do "mundo" e na interpretação pública. Ela remete a pre-sença para aquilo pelo que a angústia se angustia, para o seu próprio poder-ser-no-mundo. A angústia singulariza a pre-sença em seu próprio ser-no-mundo que, na compreensão, se projeta essencialmente para possibilidades (p. 251).

Na angústia há a possibilidade da singularidade, por isso diz-se que é uma abertura privilegiada, porque é o caminho para que o ser encontre-se a si mesmo, compreendendo-se e responsabilizando-se por si, numa liberdade que é, por princípio, constitutiva da presença enquanto ser-no-mundo.
A angústia caracteriza o sentir-se ameaçado de uma forma indefinida. (...) Nesse sentimento de afastamento de todos os entes, há solidão. O homem se sente suspenso da familiaridade do cotidiano, imerso em momentos de estranheza. Essa experiência permite, até com certo espanto, que o ser do humano compreenda o nada como o fundamento de sua existência, a origem de sua facticidade e, sobretudo, compreenda-se essencialmente livre, já que é desprovido de qualquer vínculo definitivo com o ente, ou seja, o nada é simplesmente a outra face do ser, algo quase sempre impensado (Silva, 2009, p. 96).

Heidegger esclarece que quando estamos imersos na cotidianidade, nos familiarizamos com o impessoal, que nos tranqüiliza sobre diversas questões, como a morte. Para o autor, a morte com a qual o impessoal convive é sempre a morte de alguém, entendida como um fato, mas que sempre está longe da presença. Ademais, "no domínio público, 'pensar na morte' é algo considerado como um temor covarde, uma insegurança da presença e uma fuga sinistra do mundo. $\mathrm{O}$ impessoal não permite a coragem de se assumir a angústia com a morte." (Heidegger, 1927/2002, p. 36), como a expressão bem humorada de um dos entrevistados deixa bem claro:

"Eu queria viver eternamente [risos], como no filme do Mel Gibson "Eternamente Jovem”, e não morrer, né? Dizem que o outro lado é muito bom, mas eu queria esse lado aqui mesmo, com Pronto Socorro e tudo! [risos]" (Pediatra, 30 anos de profissão).

\subsection{Os Sentimentos do Médico no Cotidiano do Ofício}

Outro aspecto passível de análise a partir das entrevistas, diz respeito a outros sentimentos vivenciados pelo médico ao deparar-se com a morte de um paciente, sentimentos esses, concluímos com Heidegger (1927/2002), derivados da angústia originada pela compreensão do ser como ser-para-a-morte. Percebemos diversas reações por parte dos profissionais, dentre as quais, destacam-se os sentimentos de fracasso, frustração, derrota, impotência, tristeza e alívio.

“(...) no atendimento da gente, né, que você acha que vai poder salvar aquela vida e não consegue, então vem aquela frustração. Vem, mesmo sendo médico há mais tempo, a gente tem. Isso acontece, a gente fica chateado (....)." (Cirurgião Geral, 35 anos de profissão).

"A morte nunca é agradável, você tem que sempre encarar como uma derrota né. (...) O médico, ele tenta lutar contra a morte, a pessoa morre, você perdeu. Então, ninguém gosta da derrota, né? E você sempre vai perder e não é só você que vai perde: vai perder a 
mãe, o pai, o filho. Então, todas essas pessoas vão ficar muito tristes, e a tristeza dos outros também entristece a gente, mesmo que não são nossos parentes, mas são pessoas" (Pediatra, 20 anos de profissão).

"Mas... algumas vezes, às vezes dá o sentimento de impotência diante de algumas situações. Não depende de você, né, mas assim... o desconforto existe e depende também de cada caso"(Clínico Geral e Homeopata, 13 anos de profissão).

"O cara ta lá numa UTI, ta praticamente morto e você não aceita, né? Você não quer! Você não quer ouvir falar que não tem mais esperança" (Pediatra, 30 anos de profissão).

Conforme salientamos anteriormente, houve um momento na história da humanidade que o desenvolvimento das ciências médicas e das tecnologias de cura e cuidado mudaram o leito de morte das pessoas de suas casas para os hospitais (Ariès, 1989). Nestes locais, a equipe de profissionais passa a ser vista como um verdadeiro exército que luta na batalha entre a vida e a morte. Então, os médicos assumem o ofício de combater a morte com todas as armas disponíveis. Só que, como foi assinalado também, esse desenvolvimento científico e a própria formação do médico enfatizam mais os aspectos técnicos de sua atuação, esquecendo-se do aspecto mais humanístico (Zaidhaft, 1990; Rasia, 2002; Silva, 2006).

Isso quer dizer que o médico vai se constituindo como aquele que vai ganhar a luta contra a morte, esquecendose que a morte faz parte da vida, é da condição humana. Assim, quando um paciente morre, a sensação é de fracasso, de derrota e de impotência, como os entrevistados revelaram vivenciar. Se, por outro lado, pensassem que sua missão é cuidar, e que nesse cuidado pode haver a cura ou não do doente, sua visão da morte seria mais natural. Conforme Bifulco (2006),

Os médicos aprenderam que sua missão é lutar contra a morte. Esgotados os seus recursos, eles saem da arena, derrotados e impotentes. Se eles soubessem que sua missão é cuidar da vida, e que a morte, tanto quanto o nascimento é parte da vida, eles ficariam até o fim (p. 164).

Mas, como vimos com Heidegger, para fugir da angústia que a morte provoca no ser, vivemos no mais ordinário das vezes, no impessoal, protegendo-nos da angústia do saber-se mortal. Assim, no caso dos médicos, os sentimentos de negação ou de não envolvimento com a situação de morte do paciente aparecem como uma forma de lidarem com o desconforto que a morte provoca, bem como de não se sentirem tão fracassados ou derrotados, como podemos perceber no seguinte dizer:
“(...) se você for ficar sofrendo com cada paciente seu que falece, você com isso... é difícil de lidar psicologicamente com isso... então, por isso que você tenta não se envolver" (Nefrologista e Clínico Geral, 20 anos de profissão).

Há também a preocupação com a rotina do trabalho, pois se os profissionais ficarem muito afetados pela morte dos pacientes correrá o risco de não darem conta do serviço. O cotidiano precisa ser preservado, pois há mais pacientes precisando do "médico combatente".

"A morte é um fato natural na vida do ser humano, e por mais que seja difícil, a gente tem que aprender a lidar com ela da melhor maneira possível. Já teve casos que eu chorei, fiquei entristecido, mas você tem que tentar levar... têm outras pessoas que precisam de você, é preciso ser forte" (Oncologista, 20 anos de profissão).

A necessidade do médico de se apegar mais ao cotidiano de suas tarefas dá a impressão que ele se importa mais com o serviço que prestou do que com o paciente. A angústia, neste caso, aparece como medo de não terem feito tudo certo e o médico, enquanto presença no mundo ocupa-se do que fez ou deixou de fazer para que aquela morte ocorresse. Todavia, pode-se perceber que essa vivência se dá para com as mortes que ocorrem de maneira "repentina" ou "inesperada", ou seja, aquelas enquadradas como "imprevisíveis".

Embora o avanço da tecnologia tenha oferecido ao médico mais suportes para retardar a finitude, fica o questionamento se utilizou todo aparato possível para fazê-lo, e quando acredita que poderia ter feito algo a mais, seja na utilização de aparelhos ou no próprio procedimento médico, a sensação é ruim, de falha, e muitos se sentem tristes e frustrados.

Por outro lado, considerando que utilizaram de todo o aparato tecnológico disponível e possível, bem como de seus conhecimentos para o caso, conseguem libertar-se da culpa ou do sentimento de fracasso gerado pela morte do paciente. É como se o médico precisasse rever em sua mente todo o processo que percorreu, para reafirmar a si mesmo que não teve culpa daquela morte, que não teve como a controlar e então, permitir-se assumir que o homem é mortal. É nesse momento que o médico consegue compreender que muitas das vezes, simplesmente não há o que ser feito, pois como nos diz Heidegger (1927/2002), a morte é um fenômeno da vida, ela está "ali", vai acontecer.

“(...) Às vezes um desânimo, né, você fica, poxa vida, será que eu, não... será que eu fiz a coisa certa? Ou, será que se eu tivesse feito diferente eu não teria, não teria tido um melhor resultado? Esse tipo de coisa assim, hoje já nem tanto, pela experiência que a gente 
já tem de 35 anos já, né, mas no início era estressante, né” (Cirurgião Geral, 35 anos de profissão).

“(...) você fica vendo o sangue, você fica vendo, imaginando será que teria alguma coisa aí que eu poderia fazer, será aquilo, não tem o que fazer?. Chegou a hora e acabou. (...) o tempo cura muita coisa, lógico que às vezes fica aquela feridinha, mas só que quando é um óbito que você sabe que você fez o possível, não tem ferida, tem assim, o desgosto de ter visto a pessoa morrer, então você tem que encarar que você fez o que era possível” (Pediatra, 20 anos de profissão).

“(..) na minha área, como é a ginecologia, quando tem um óbito né, uma morte... na maioria das vezes aconteceu alguma coisa antes que poderia, às vezes evitar essa morte. Então a gente se sente frustrado com essa morte. (...)Mas eu acho que você tendo os exames em mãos, tendo os diagnósticos que te permite saber como aconteceu isso, facilita bastante para você conseguir conviver com isso" (Ginecologista, 10 anos de profissão).

"Você ofereceu pra ele até quando ele estava nos seus momentos finais de vida, você ofereceu um conforto pra que ele pudesse ter uma dignidade no final de vida. Então, quando você faz todo esse tipo de coisa, você se sente satisfeito por ter feito o seu bom serviço, e você tem a certeza de que a morte para este paciente não foi... foi simplesmente uma conseqüência da vida, e não que esse paciente tenha sido um fracasso na tua prática médica” (Nefrologista e Clínico Geral, 20 anos de profissão).

Nos relatos colhidos, chamou atenção a frequência com que a morte infantil ou de jovens foi tratada como foco de sofrimento exacerbado por parte dos profissionais médicos. O que ficou registrado é que a morte de uma criança é inadmissível, inesperada e muito difícil de ser elaborada e aceita, sentimentos esses que intensificam a sensação de derrota e fracasso que tratamos há pouco.

Hoffman (1993) aponta que há dois modos de se considerar a morte em um hospital. O primeiro diz respeito às mortes esperadas, que integram os acontecimentos previstos num determinado setor do hospital e, o segundo, fica a cargo das mortes não previstas, que simplesmente não poderiam acontecer. Na pesquisa, ficou evidente que as mortes infanto-juvenis foram enquadradas na última modalidade.

"Teve uma vez um caso que me entristeceu um pouco de um garotinho de 5 anos que foi atropelado. Chegou já quase em óbito... não teve muito o que fazer. Mas você vê que é criança né, aí a gente fica mais comovido, a gente não espera que vai morrer, não quer que morre (...)” (Clínico Geral, 7 anos de profissão).
“(...) tem pacientes graves, tem pacientes com HIV, tem pacientes com problemas neurológicos né, neuropatias, que vão morrer cedo, infelizmente! (...) quando chega uma criança hígida, sofreu um acidente, não se compara! (...) É triste, né, uma menininha de três, quatro anos e você saber que vai morrer. Mesmo depois da cirurgia você viu que não vai viver" (Pediatra, 20 anos de profissão).

"Uma coisa é você pegar um óbito de uma criança vítima de uma, de um caso de uma morte violenta, e outra coisa é você pegar uma pessoa com noventa anos que morreu de uma morte natural" (Clínico e Homeopata, 13 anos de profissão).

“(...) acho que quando é uma morte que já é previsível, quando a paciente já tem um câncer uma coisa assim, isso é mais bem aceito, entendeu? E quando morre um bebê? Péssimo. Principalmente quando a mãe, a gestante em geral, ela ta pronta pra uma alegria, não é? E quando você tem esse óbito dessa criança, então é uma tristeza incrível... é realmente difícil” (Ginecologista, 10 anos de profissão).

A criança é a depositária do narcisismo do adulto, que também se esvai com a morte, levando o símbolo da imortalidade representada pelo significado de vida que se traduz na criança. Zaidhaft (1990) pontua que a morte de crianças talvez seja inconcebível, pois representa um ciclo de vida que não se cumpriu, haja vista que as etapas normais e esperadas seguem a linha da infância, adolescência, fase adulta e velhice. Trata-se da morte de um futuro cheio de possibilidades, como assinalaram dois pediatras:

“(...) a criança bateu de moto, uma menina bonita e... morrer... sem ter causa nenhuma assim de doença que foi destruindo o corpo dela. Não, foi uma pancada e morreu subitamente...isso é triste! Muito triste! Você ver uma pessoa cheia de sonhos, cheia de esperanças e... acabou” (Pediatra, 20 anos de profissão).

“(...) é muito difícil né, principalmente uma criança né, que ta começando a vida né, que você imagina assim, um futuro assim, muito longo pra ela né, então você realmente é difícil de aceitar. Você acha que tudo é saúde, tem que ser saúde pra criança, porque ela ta no início, ela é o alfa, não é o ômega ainda... então é assim que funciona, então a gente... lógico que você vai lidando, vai convivendo com isso, mas não vai aceitar normalmente... isso você não aceita né?” (Pediatra, 30 anos de profissão).

Elias (2001, p. 77) reconhece que para nós "é terrível quando pessoas morrem jovens, antes que tenham sido capazes de dar um sentido às suas vidas e de experimen- 
tar suas alegrias". Mas Heidegger (1927/2002) lembra que desde o seu nascimento o homem já é suficientemente velho para morrer. Segundo o filósofo, todo ser já nasce sendo presença no mundo e carregando em si todas as suas possibilidades de ser, e nelas já está a possibilidade do não-ser, que é também sua possibilidade mais certa.

É difícil aceitar que não existe uma "ordem cronológica natural” que estipula o acontecer da morte, ainda mais se considerarmos as conquistas que a ciência nos possibilitou em se tratando do aumento da expectativa de vida. A morte pode ser adiada em decorrência dessas conquistas, contudo ela ainda é incontornável, incontrolável e inarredável. Apesar dessas conquistas ainda não estamos agarrados a nada enquanto presença no mundo, mas nos iludimos:

(...) a medicina desnuda a morte buscando munir-se, através dela, de conhecimentos e de técnicas para ludibriar, ou pelo menos adiar, a finitude humana. Assim, morrer de velhice passa a ser considerada forma de morte natural. Por conseqüência, todas as outras maneiras de se morrer são consideradas contra a natureza e, por isso, mortes desnecessárias (Bellato, citado por Haddad, 2006, p. 39).

Mesmo que o "discurso" da certeza da morte seja característico de todos, em que a presença se refugia no impessoal, parece difícil encarar que isso ocorra tão cedo. Uma criança representa a vida, os sonhos, "o futuro", e interromper tantas expectativas, definitivamente não é algo bem quisto nem aceitável.

Com relação ao modo com o qual lidam com essas situações, vários entrevistados mencionaram que a formação médica deveria ser mais atenta aos aspectos envolvidos no "lidar com a morte no ofício". Entendem que isso poderia amenizar a angústia e oferecer uma prática médica mais eficiente. A maioria dos médicos relataram que não tiveram subsídios, na sua formação, para "enfrentar a morte".

"Na faculdade não tem essa... mesmo quando você faz a cadeira da Psicologia não se aborda a morte, se aborda patologias, né, como se trata as patologias dos pacientes, você não trata o médico né, como ele vai ter que lidar com aquela patologia, como ele vai ter que responder para aquela patologia. Na minha faculdade não existiu, acho que até poucos anos atrás nenhuma faculdade deveria ter, não sei como que ta agora. Agora, nunca houve preparação de como você deve lidar com a morte, ou com os parentes do paciente que foi ao óbito, né” (Pediatra, 20 anos de profissão).

"Nada! Que nada! Ninguém me avisou! Do mesmo jeito que não me avisaram qual especialidade ia ser melhor, também não me avisaram que a morte é assim e você ia ter que lidar (...) E não fomos ensinados, de quando morrer, não sabemos conviver com isso, pelo menos eu né?” (Pediatra, 30 anos de profissão).

“(..) na academia mesmo foi muito pouco o que recebemos de informação que tratasse da morte. Talvez um ou outro professor, das cadeiras que faziam a gente refletir mais sobre isso né, a Psicologia Médica, ou a Medicina Legal” (Oncologista, 20 anos de profissão).

"Tivemos a cadeira de Psicologia Médica né, que tratava um pouco sobre a morte, também em Medicina Legal falaram alguma coisa. Mas ninguém me ensinou como eu tenho que lidar com isso... acho que lidar com a morte é uma coisa muito pessoal. Só que tem que ser forte, senão não agüenta, enlouquece” (Clínico Geral, 7 anos de profissão).

Apenas dois dos dez entrevistados reconheceram ter recebido, de forma efetiva, uma atenção em nível acadêmico com relação à morte, conforme nos revelam as seguintes palavras:

“(..) existe até a cadeira em que a gente é orientado a como proceder em determinados tipos de situações, né” (Cirurgião Geral, 35 anos de profissão).

"Eu tive psicologia né... psicologia, psicologia hospitalar. Foi uma psicóloga que deu e nós discutimos sobre isso, sobre a morte e o morrer. Foi legal... na época foi bem interessante, ajudou bastante” (Clínico Geral e Homeopata, 13 anos de profissão).

Nossos entrevistados nos falam de uma vivência na graduação, que de maneira geral, apresenta carência do preparo do estudante de medicina para lidar com a morte e o morrer de um paciente, o que não é diferente daquilo que a literatura especializada aponta. Vale ressaltar que a literatura também se refere à necessidade de um preparo maior e melhor pelos cursos de graduação em Medicina, para que os alunos aprendam e desenvolvam habilidades para lidar com as situações que a morte traz em seu ofício. Isso também foi compartilhado por alguns dos profissionais entrevistados.

"Ah, eu acho que tinha que ter uma preparação, porque até hoje, quando tem pacientes que vão à óbito, eu prefiro chamar o Serviço Social, a psicóloga vai lá falar com a mãe do que eu ir, porque eu já to sofrendo muito pra ver a outra pessoa sofrer" (Pediatra, 20 anos de profissão).

"Olha, realmente eu acho que é um assunto que deveria ser trabalhado, viu. Porque tem pessoas que naturalmente, talvez até já venha isso de casa, de berço como se diz, já tem isso nela. Agora, muitas pessoas não têm e isso precisa ser trabalhado, sabe? São pes- 
soas extremamente que assim... têm uma certa frieza ali, as vezes pode ser uma insegurança, pode ser... sei lá. A gente não sabe né, mas é ruim pros pacientes, pros familiares e pra própria pessoa. Com o tempo ela acaba se complicando com isso. Então eu acho que tem que saber trabalhar, tem que saber elaborar esses sentimentos e não se tornar algo que muitas vezes as pessoas falam... ah, é frio, é insensível. Eu acho que é algo que tem que ser trabalhado e elaborado, porque como ser humano, o médico sofre e tem que saber lidar com essas situações... e isso deve se iniciar lá na escola... na formação” (Clínico Geral e Homeopata, 13 anos de profissão).

Podemos pensar que os médicos tenham reconhecido essa importância, porque sofrem com os desconsolos de uma prática que, em última instância, não consegue combater a morte; mas que têm de conviver com ela de forma amigável. Todos os aspectos trazidos aqui, refletem vozes que necessitam ser compreendidas atentamente, para que mudanças se efetivem na direção de um cuidado autêntico aos envolvidos na atenção em saúde, profissionais e doentes, todos na condição de existirem no mundo como ser-para-a-morte.

\section{Considerações Finais}

O médico se angustia diante da morte, como qualquer outro ser-no-mundo. O cotidiano de sua prática profissional não o deixa "acostumado" com a morte, não o faz lidar mais "facilmente" com a morte, não a faz ser algo comum de se pensar. Pelo contrário, o estudo nos mostrou que o ser-aí-médico está mais sujeito a encobrir-se na impessoalidade e na inautenticidade do cotidiano, pois a angústia que a morte lhe desperta não é constitutiva somente da sua condição humana, mas também faz parte das contingências de sua ocupação profissional. Podemos dizer que ele fica "mais exposto" a essa angústia e por isso, com mais intensidade, procura afastar-se dela ocupando-se com as rotinas do cotidiano, desatendendo ao que a angústia convoca. Esse “encobrimento” também acontece na própria formação médica, que não se dedica a meditar sobre a condição humana. Nesse sentido, ao médico não são oferecidas oportunidades para que conviva com essa angústia e todos os sentimentos advindos dela, seja pelo ritmo do trabalho, seja pelo ritmo da sua formação, ambos fundamentados num paradigma científico que ainda prima pelo controle e pela cura; que bem pouco assume certas impossibilidades e fragilidades humanas; que bem pouco se ocupa do cuidado. Ao que a angústia convoca? Convoca-nos à ser-si-próprios, a projetar uma existência que tenha sentido para nós.

Heidegger (1927/2002) entende que o ente humano é presença no mundo, ou seja, o ser do humano se manifesta sendo-aí no mundo, mundo esse compartilhado. $\mathrm{O}$ compartilhamento do mundo se dá no encontro da presença com a co-presença dos outros, antes de tudo e na maior parte das vezes, nas ocupações do mundo próximo. Empenhando-se no mundo das ocupações, que nada mais é o ser-com-os-outros, a presença pode ser também o que ela não é, ou seja, ela pode assumir a possibilidade de não ser-no-mundo de modo próprio, ou seja, de viver no mundo como se esse viver não fosse seu, não fosse de propriedade e responsabilidade sua. A angústia que a morte nos revela nos convoca e essa propriedade e à responsabilidade de ser.

É dessa responsabilidade que fugimos. Fugimos para o impessoal, para o inautêntico. O impessoal tranqüiliza a presença; dá-se um velamento do ser-para-o-fim, sendo construída uma indiferença pretensamente imperturbável em relação à possibilidade extrema de sua existência. E aí o médico sofre as agruras do ser-médico, pois "esconde-se" em sua prática cotidiana, na qual procura proteger-se da morte, daquilo que ela suscita.

Ao contrário do que se poderia pensar, como todos nós, o médico se sente estranho diante da morte. Mas isso poderia ser minorado, pois segundo a experiência que compartilharam conosco durante esse estudo, essa estranheza vivida pelo médico frente à morte, se dá não só pela sua condição de ser-mortal, mas, junto com ela, pela ausência de espaços de reflexões acerca da finitude, uma vez que a morte em nossa sociedade é tida como algo indesejado e que deve ser silenciada, resultando no temor em pensar sobre ela. Dentre esses possíveis espaços está a formação acadêmica, que peca no preparo do estudante de medicina para a reflexão dos aspectos inerentes ao luto, à morte e ao morrer.

Neste sentido, os achados da pesquisa alertam para a importância da criação de projetos de graduação que contemplem a temática morte como foco de discussão e reflexões, bem como a criação de espaços, no ambiente de formação e de trabalho, para que seja possível o compartilhamento da angústia, dos medos e dos sentimentos de dor, como forma de humanizar o ofício médico, o que teria repercussões positivas também no trato com pacientes e familiares. Isso não arredará a angústia inerente ao compreender-se ser-para-a-morte, mas sem dúvida, proporcionará um ambiente psicológico acolhedor para que o médico possa melhor cuidar e ser cuidado.

\section{Referências}

Ariès, P. (1989). História da morte no ocidente: da idade média aos nossos dias. Rio de Janeiro: Francisco Alves.

Bifulco, V. A. (2006). A morte na formação dos profissionais de saúde. Prática Hospitalar, 8 (45), 164-166.

Elias, N. (2001). A solidão dos moribundos, seguidos de envelhecer e morrer. Rio de Janeiro: Jorge Zahar. 
Feijoo, A. M. L. C. (1998). A psicoterapia existencial: uma pesquisa fenomenológica. Em V. A. Angerami (Org.), A prática da psicoterapia (pp. 22-26). São Paulo: Pioneira.

Haddad, D. R. S. (2006) A morte e o processo de morrer de crianças em terapia intensiva pediátrica: vivências do enfermeiro. Dissertação de Mestrado, Escola de Enfermagem, Universidade Federal de Minas Gerais, Belo Horizonte.

Heidegger, M. (2002). Ser e Tempo. Petrópolis: Vozes (Original publicado em 1927).

Hoffmann, L. (1993). A morte na infância e sua representação para o médico - reflexões sobre a prática pediátrica em diferentes contextos. Cadernos de Saúde Pública, 9 (3), 364-74.

Klafke, T. E. (1998) O médico lidando com a morte: aspectos da relação médico-paciente terminal em cancerologia. Em R. Cassorla (Org.), Da morte (pp. 25-50). Campinas: Papirus.

Koifman, L. (2001) O modelo biomédico e a reformulação do currículo médico da Universidade Federal Fluminense. História, Ciências, Saúde - Manguinhos, 8 (1), 48-70. Rio de Janeiro.

Mascia, A. R., Silva, F. B., Lucchese, A. C., De Marco, M. A., Martins, M. C. F. N., \& Martins, L. A. N. (2009). Atitudes frente a aspectos relevantes da prática médica: estudo transversal randomizado com alunos de segundo e sexto ano. Revista Brasileira de Educação Médica, 33 (1), 40-48.
Rasia, J. M. (2002). O doutor e seus doentes: solidão e sofrimento. Revista Brasileira de Sociologia da Emoção, 1 (3), 341-365.

Silva, G. S. N. (2006). A construção do "ser médico" e a morte: significados e implicações para a humanização do cuidado. Tese de Doutorado, Faculdade de Medicina, Universidade de São Paulo, São Paulo.

Silva, L. C. (2009). O cuidado na vivência do doente de câncer: uma compreensão fenomenológica. Maringá: Eduem.

Zaidhaft, S.(1990). Morte e formação médica. Rio de Janeiro: Francisco Alves.

Aline Andressa Martinez Mello - Psicóloga, graduada pela Universidade Estadual de Maringá. Endereço para correspondência: Rua João José Bortolatto, 22. CEP: 87053-649. Maringá/PR. E-mail: andressa.aline@gmail.com

Lucia Cecília da Silva - Doutora em Psicologia e Professora Adjunta da Universidade Estadual de Maringá. Endereço para correspondência: Departamento de Psicologia, Universidade Estadual de Maringá. Av. Colombo, 5790. CEP: 87020-900. Maringá/PR. E-mail: lcsilva2@uem.br

Recebido em 14.07.2011

Primeira Decisão Editorial em 16.11.2011

Aceito em 14.02.2012 